\title{
ARTIGOS
}

\section{O LEGADO DE VIRGÍNIA LEONE BICUDO PARA A SOCIOLOGIA DA INFÂNCIA NO BRASIL}

\section{ELISÂNGELA DA SILVA SANTOS'}

\section{RESUMO}

Este artigo tem como objetivo realizar uma análise do texto "Atitudes dos alunos dos grupos escolares em relação com a cor de seus colegas", de autoria da socióloga e psicanalista Virgínia Leone Bicudo (1955). Nessa pesquisa, Bicudo analisou o cotidiano escolar e familiar dos alunos, com foco em categorias como raça, gênero e nacionalidade, fornecendo um mapa analítico na perspectiva das ciências sociais para a análise transdisciplinar da infância, transcendendo os limites biológicos e geracionais. Parte-se de uma revisão de literatura sobre a constituição do campo de pesquisas sobre a infância no Brasil e da inserção e contribuições desta autora para a área. Apostamos na hipótese de que o trabalho de Bicudo pode ser lido como um dos primeiros que enfatizaram a singularidade das atitudes raciais infantis, sendo as próprias crianças as principais informantes e participantes, por meio de entrevistas.

BICUDO, VIRGÍNIA LEONE・SOCIOLOGIA • INFÂNCIA • RAÇA

\section{THE LEGACY OF VIRGINIA LEONE BICUDO FOR THE SOCIOLOGY OF CHILDHOOD IN BRAZIL}

\section{ABSTRACT}

This article aims to conduct an analysis of the text "Atitudes dos alunos dos grupos escolares em relação com a cor de seus colegas [Attitudes of students of public school in relation to the color of their colleagues]", authored by the sociologist and psychoanalyst Virginia Leone Bicudo (1955). In this study, Bicudo examined the everyday school and family context of students, focusing on categories like race, gender and nationality, providing an analytical map from the perspective of the social sciences for the transdisciplinary analysis of childhood, transcending the biological and generational boundaries. This study was based on a review of the literature regarding the development of the field of research on childhood in Brazil, and the insertion and contributions of this author to the area. We believe that Bicudo's work is one of the first that emphasized the individuality of children's racial attitudes. The children themselves were the main informants and participants, through interviews. 


\section{L'HÉRITAGE DE VIRGÍNIA LEONE BICUDO POUR LA SOCIOLOGIE DE L’ENFANCE AU BRÉSIL \\ RÉSUMÉ}

L'objectif de cet article est d'analyser le texte "Atitudes dos alunos dos grupos escolares em relação com a cor de seus colegas [Attitudes des élèves des groupes scolaires concernant la couleur de leurs camarades]", rédigé par la sociologue et psychanalyste Virgínia Leone Bicudo (1955). Dans cette recherche, Bicudo a analysé le quotidien scolaire et familial des élèves, axée sur des catégories comme la race, le genre et la nationalité, afin de fournir une carte analytique dans la perspective des sciences sociales pour l'analyse transdisciplinaire de l'enfance, qui dépasse les limites biologiques et générationnelles. Ce travail part d'une révision de la littérature sur la formation du champ de la recherche concernant l'enfance et l'inclusion au Brésil, et des contributions de l' auteure dans ce domaine. Nous soutenons l'hypothèse que le travail de Bicudo peut être lu comme un des premiers à avoir insisté sur la singularité des attitudes vis à vis la race des enfants, qui, par le biais d'entretiens, ont été non seulement les participants mais aussi les principaux informateurs.

BICUDO, VIRGÍNIA LEONE・SOCIOLOGIE • ENFANCE • RACE

\section{EL LEGADO DE VIRGINIA LEONE BICUDO PARA LA SOCIOLOGÍA DE LA INFANCIA EN BRASIL}

\section{RESUMEN}

Este artículo tiene como objetivo realizar un análisis del texto "Atitudes dos alunos dos grupos escolares em relação com a cor de seus colegas [Actitudes de los alumnos de los grupos escolares en relación con el color de sus colegas]", de autoría de la socióloga y psicoanalista Virgínia Leone Bicudo (1955). En esta investigación, Bicudo analizó el cotidiano escolar y familiar de los alumnos, con foco en categorías como raza, género y nacionalidad, proporcionando un mapa analítico en la perspectiva de las ciencias sociales para el análisis transdisciplinario de la infancia, trascendiendo los límites biológicos y generacionales. Se parte de una revisión de literatura sobre la constitución del campo de investigaciones sobre la infancia en Brasil y de la inserción y contribuciones de esta autora al área. Apostamos en la hipótesis de que el trabajo de Bicudo puede ser leído como uno de los primeros que enfatizaron la singularidad de las actitudes raciales infantiles, siendo los propios niños los principales informantes y participantes, por medio de entrevistas. 
Colocar em foco a hierarquia racial como geradora de contradicões sociais que se articulam às relações de classe, parece-me, nos planos do conhecimento e da ação prática, uma perspectiva para compreender e transformar o sistema educacional em sociedades multirraciais. (ROSEMBERG, 1991, p. 26)

URANTE LONGO PERÍOdo, A CRIANÇA PEQUENA, RECONHECIDA COMO ATUANTE socialmente, não obteve centralidade nas áreas de estudos das ciências sociais. A década de 1980 trouxe como um dos grandes marcos a discussão desta temática sob novas perspectivas. No caso brasileiro, a Constituição de 1988 é reconhecida como um importante emblema, pois as crianças tiveram seu direito às creches e pré-escolas reconhecido formalmente, pauta que assinalou as discussões de diversos movimentos sociais emergidos nos anos 1970 e 1980.

Como sublinha Anete Abramowicz (2011), desde o século XVIII, tem-se elaborado um conjunto de saberes sobre a infância, um conceito disputado entre os diversos campos do conhecimento, bem como dentro de um mesmo campo, por exemplo, da sociologia da infância. A infância ora é uma estrutura universal, constante e característica de todas as sociedades, ora é um conceito geracional, uma variável sociológica que se articula à diversidade da vida das crianças; por algumas perspectivas é vista como plural, enquanto por outras é encarada como singular.

Considerando as perspectivas da singularidade e da pluralidade infantil, essa reflexão tem como objetivo discutir a pesquisa de Virgínia Leone Bicudo (1955), realizada na década de 1950, intitulada "Atitudes dos alunos dos grupos escolares em relação com a cor de seus colegas”. Nossa hipótese é de que essa pesquisa, ao problematizar a condição das crianças - meninas, meninos, brancas, negras, imigrantes - que dividiam o espaço escolar, apontou que estereótipos, preconceitos, discriminação 
e desigualdades eram premissas que também faziam parte do universo infantil e, por isso, sua perspectiva nos fornece instrumentos analíticos capazes de interconectar a sociologia, a psicologia infantil e a educação. O objetivo de Bicudo foi compreender como a escola segmenta seus espaços por meio das atitudes de seus agentes.

Para melhor compreensão do debate aqui proposto, o trabalho está estruturado em três partes. Nesta introdução é realizada uma localização de como esse estudo da autora se inseriu no processo de consolidação e constituição de um campo de pesquisa sobre as relações raciais na sociedade brasileira, e quais eram as preocupações recorrentes de intelectuais que se agruparam em torno de um projeto de pesquisa caudatário das discussões acerca das relações raciais no concerto das Nações Unidas. Na segunda parte apresentam-se as incursões de Virgínia Bicudo na temática da infância e educação, pautas muito discutidas no início do século XX e que se uniram às pautas de projetos políticos e sociais para a população, incluindo a população infantil. Por fim, é feita a análise do resultado de seu trabalho desenvolvido no projeto Unesco/Anhembi, tendo como objetivo demonstrar sua grande contribuição para os estudos da sociologia da infância no Brasil.

A autora desempenhou diversas funções na ciência brasileira, tais como educadora sanitária, visitadora psiquiátrica, cientista social, professora universitária, psicanalista, divulgadora científica e protagonista de diversas iniciativas no plano da institucionalização da psicanálise no Brasil. ${ }^{1}$ Ela integra uma geração de intelectuais cuja trajetória está muito atrelada ao processo de institucionalização das ciências sociais e da psicanálise no Brasil.

Sua investigação é resultado de estudos exemplares e pioneiros que culminaram no aprimoramento da prática da pesquisa social com crianças e, na nossa visão, pode também ser encarada como precedente da mudança epistemológica que marcou a chamada sociologia da infância na década de 1980, uma vez que permite questionar a inserção de crianças na vida social da cidade de São Paulo dos anos 1950, bem como o problema das “relações raciais”. Nessas análises, as crianças são vistas como protagonistas, pois são as principais informantes dos processos sociais e mentais a que estavam sujeitas.

\footnotetext{
Pela primeira vez vemos um esforço para pesquisar o preconceito racial, tendo instituições de ensino como lócus privilegiado de investigação. Em comum, além disso, a recorrência do indivíduo como fonte de uma preocupação de informações e desenvolvimento de uma preocupação com a formação de subjetividades pautadas na experiência em comum de determinados grupos no meio urbano. (GOMES, 2013, p. 65)
} 
A autora adentrou o cotidiano escolar e, ao mesmo tempo, transcendeu esse espaço num período em que a própria sociologia da educação, cujo espaço de análise se pautava basicamente no contexto escolar, estava sendo formulada enquanto um campo de conhecimento acadêmico. É importante ressaltar que houve uma valorização das experiências infantis, pois as crianças partícipes da pesquisa tiveram suas experiências de vida contadas, o que possibilitou trazer a multiplicidade de vivências com origens sociais, étnicas, familiares e de gênero distintas. Desse modo, podemos dizer que houve um olhar transdisciplinar sobre a infância, comumente analisada pela vertente biologizante e essencialista.

Neste sentido, cabe observar que o acúmulo das pesquisas desenvolvidas no campo da história da infância tem possibilitado flagrar uma diversidade de processos históricos, evidenciando que a experiência da infância diferencia-se de acordo com categorias sociais definidoras da identidade infantil, categorias essas que vêm sendo contempladas, em seu entrelaçamento, nas investigações mais recentes. Assim, já não é possível falar da infância no singular, mas nas múltiplas vivências dos indivíduos de pouca idade, definidas por seu pertencimento social, étnico-racial, religioso, de gênero, etc. (ROCHA; GOUVEA, 2010, p. 189)

O trabalho de Bicudo em questão integrou o relatório do inquérito Unesco/Anhembi sobre as relações raciais entre negros e brancos em São Paulo. É importante ressaltar que esse período foi de extrema importância para o desenvolvimento de pesquisas sociais no Brasil. Entre 1951 e 1952, a Organização das Nações Unidas para a Educação, Ciência e Cultura (Unesco) patrocinou uma série de investigações sobre as relações raciais no Brasil.

Conforme Maio (1999), o objetivo era apresentar ao mundo os detalhes de uma experiência no campo das interações raciais, julgada, na época, singular e bem-sucedida tanto interna quanto externamente. Esse programa investigativo, conhecido como Projeto Unesco, não apenas gerou um amplo e diversificado quadro das relações raciais no Brasil, como também contribuiu para o surgimento de novas leituras acerca da sociedade brasileira, em contexto de rápido processo de modernização.

O ciclo de pesquisas ofertou grandes possibilidades para o desenvolvimento das ciências sociais no Brasil dos anos 1950. A agenda de pesquisa anos antes sintetizada pelo antropólogo Arthur Ramos (1903-1949) inscrevia para a inteligência do país, inserida na universidade, o desafio de associar a qualificação profissional nos campos da Antropologia e da Sociologia, além do incentivo às pesquisas capazes de decifrar o que este 
autor considerava como a singularidade nacional, vista como "laboratório de civilização”.

Do outro lado, a revista Anhembi (1950-1962), idealizada e criada pelo jornalista paulista Paulo Duarte (1889-1984), representou naquele momento um espaço de debate bastante importante na cidade de São Paulo, com a divulgação de conhecimentos e pesquisas de intelectuais brasileiros e estrangeiros. Além da publicação de artigos que procuravam enfatizar o aspecto científico das pesquisas em desenvolvimento, a revista dedicava-se a abordar criticamente os acontecimentos do mês corrente. Paulo Duarte fez contato com Roger Bastide (1898-1974) no início dos anos 1950 com o objetivo de realizar uma pesquisa sobre o negro no Brasil, e este, por sua vez, convidou Florestan Fernandes (1920-1995) como seu colaborador. Naquele momento já estava em curso o processo de organização da pesquisa Unesco e o intercâmbio de Alfred Metraux (1902-1963), do Departamento de Relações Raciais da Unesco, para o trabalho em conjunto:

O trabalho, considerado em conjunto, aborda três grandes temas: o
debate sobre as bases escravocratas das relações sociais no Brasil;
a mudança social e a questão da cor como obstáculo à mobilida-
de; o preconceito de cor, suas manifestações, seus efeitos e a luta
para superá-lo. Colaboraram, como responsáveis pelos textos -
além dos já citados Roger Bastide e Florestan Fernandes - Virgínia
Bicudo, Aniela Ginsberg e Oracy Nogueira. (BASTOS, 2007, p. 257)

Na introdução do livro Relações raciais entre negros e brancos em São Paulo, resultante da investigação, Bastide (1955a, p. 11) aponta que a escolha para a realização da pesquisa na cidade de São Paulo

[...] apresenta, para o estudo do preconceito de cor, um significado especial, pois transformou-se, em menos de meio século, de uma cidade tradicional numa metrópole tentacular, o maior centro industrial da América Latina.

Bicudo integrou a equipe do projeto Unesco/Anhembi, ${ }^{2}$ desenvolvido entre 1951 e 1953, coordenada pelo sociólogo e antropólogo francês Roger Bastide; seu nome foi sugerido por Otto Klineberg (1899-1992), professor de psicologia social da Universidade de Columbia, que atuou como professor na Universidade de São Paulo (USP) de 1945 a 1947, com o objetivo de trazer a experiência norte-americana no campo da psicologia social para o Brasil e criar o Departamento de Psicologia da USP.

Maio (1999) ainda destaca que Klineberg era diretor interino do Departamento de Ciências Sociais e consultor da Unesco na definição da pesquisa sobre relações inter-raciais no Brasil. Ao sugerir o nome

2

Na segunda edição do livro resultado da pesquisa Unesco/Anhembi, de 1959, os trabalhos de Bicudo e de Ginsberg foram retirados. Segundo Segura-Ramírez (2006), os trabalhos de ambas foram publicados como "documentos" ou "protocolos" de pesquisas, já que não faziam parte do projeto original. Para este pesquisador, chamou a atenção a hierarquização, pois seus trabalhos seguiam uma linha das dimensões psíquicas e comportamentais. 
de Bicudo, ele escreveu um documento endereçado ao etnólogo Alfred Metraux, chefe do Setor de Estudos sobre Raça do mesmo departamento da Unesco, informando que a socióloga encontrava-se na Divisão de Saúde Mental da Secretaria da Educação de São Paulo, trabalhando com Durval Marcondes (1899-1981), e que havia defendido uma dissertação de mestrado (a primeira na área) muito boa sobre as atitudes dos negros nas relações entre negros e brancos em São Paulo, trabalho orientado por Donald Pierson (1900-1995), na Escola Livre de Sociologia Paulista.

Assim surge o texto objeto deste artigo, resultado da atuação de Virgínia Bicudo no projeto Unesco, que buscava nas experiências infantis seu objeto de pesquisa sobre as chamadas atitudes raciais. Segundo Gomes (2013), sua função como visitadora psiquiátrica possibilitou abordar o chamado "ajustamento da personalidade" dos escolares, analisando o ambiente afetivo dos estudantes, como precursora de muitos estudos no Brasil envolvendo a infância. Esse processo foi realizado num momento em que a profissão de socióloga e a pesquisa de campo nas grandes cidades ainda eram incipientes. Nessa pesquisa, o foco foi a criança, logo, a família e a escola, pois é nessas esferas que o preconceito se espalha, já que ali é aprendido e ensinado.

De acordo com Segura-Ramírez (2006), a escola e a família são duas instâncias focalizadas por Bicudo na interface entre psicologia e relações raciais; suas ferramentas epistemológicas da análise foram a teoria psicológica, a análise estatística e o estudo de caso. A autora percebe que os estereótipos se tornam uma realidade psicológica de importância primordial, a qual exerce uma influência determinada sobre as relações entre os grupos e sobre os comportamentos de cada grupo.

É importante ressaltar que os campos pedagógico e psicológico foram por muito tempo pautados pelas prescrições derivadas do campo médico higiênico, e que a institucionalização da infância no Brasil estava profundamente atrelada a projetos políticos e sociais para a população infantil, sendo que tais projetos se alicerçavam em bases demográficas, higiene pública, modernização e urbanização. A pesquisa de Bicudo trouxe como grande possibilidade a reflexão sobre como as diferenças raciais operavam nas diversas formas de socialização.

\section{VIRGÍNIA LEONE BICUDO E O INÍCIO DAS PESQUISAS SOBRE A INFÂNCIA}

De acordo com Abrão (2010), Virgínia Bicudo foi uma expressiva representante de seu tempo, sendo que as iniciativas que empreendeu durante sua trajetória pessoal e profissional refletem a conjugação de uma personalidade arguta e tenaz com as transformações em ritmo frenético que marcaram a urbanização e a industrialização da cidade de São Paulo durante o século XX. 
Bicudo nasceu em 1910, filha de uma imigrante pobre italiana (Joana Leone) e de um descendente de escravo e afilhado de fazendeiro de café em Campinas (Teófilo Bicudo). Como comenta Maio (2010), seu pai se transferiu para a cidade de São Paulo com o objetivo de estudar e, por influência política do padrinho, iniciou seu trabalho nos Correios e Telégrafos, onde veio a se tornar alto funcionário. Bicudo, quando nasceu, vivia no bairro da Luz, formado a partir do século XIX, local onde viviam muitos imigrantes italianos e onde a autora passou toda sua infância e adolescência.

As transformações vivenciadas por ela em meio a todo o processo de urbanização que assolava a cidade de São Paulo reverberaram, conforme Abrão (2010), tanto na sua compreensão sobre as relações humanas quanto nas práticas profissionais que exerceu. Naquele momento o país vivenciava um processo de renovação das ideias pedagógicas, uma nova filosofia que ficou conhecida como "Escola Nova", além da adoção, no campo da saúde mental, de uma proposta de intervenção preventiva nas crianças, que ficou conhecida como "higiene mental".

A nova política educacional partia do princípio de que a escola deveria atuar como elemento para edificar a sociedade por meio da valorização das qualidades pessoais e do desenvolvimento das potencialidades de cada aluno. Após concluir o curso normal, Bicudo ingressou, em 1932, no Instituto de Higiene, com a finalidade de fazer o curso de Educadora Sanitária. Este curso, idealizado por Geraldo Horário de Paula Souza (1889-1951), foi criado em 1925 e extinto em 1962. O objetivo era formar profissionais especializados que promovessem um conjunto de ações profiláticas instituídas pela saúde pública do período.

De acordo com Heloísa Rocha (2005), o Instituto possuía uma atuação prática que visava impressionar e convencer a importância dos hábitos de higiene em espaços que iam dos recém-criados centros de saúde, escolas, hospitais, fábricas, até as próprias casas. As iniciativas das educadoras sanitárias tinham na infância seu alvo prioritário, procurando, por meio das crianças, atingir suas famílias, ensinando-lhes um padrão de vida considerado civilizado, expresso em práticas desejáveis de asseio pessoal e do vestuário, higiene do lar, alimentação e cuidado com os filhos.

Saúde, instrução e moral constituíam o tripé sobre o qual se assentava a atividade dessas "mensageiras da saúde", incumbidas de "regenerar a raça”.

Assim, se a opção pela educação sanitária significou uma mudança do campo educacional para o campo da saúde pública, tal mudança não se consubstanciou num afastamento das atividades ligadas à socialização das crianças e ao cuidado; tarefas que, historicamente, foram sendo consideradas como ocupações femininas, 
espécie de extensão das atividades domésticas, parte das funções maternas que cabiam às mulheres. Tornar-se educadora sanitária representou, desse modo, a inserção em um espaço de atuação profissional que foi se constituindo em continuidade ao magistério, o qual, desde a virada do século, vinha se tornando uma profissão dominantemente feminina. (ROCHA, 2005, p. 79)

Conforme ressaltam Kuhlmann Júnior e Magalhães (2010, p. 328), a autoridade dada pela ciência naquela época podia ser observada nos almanaques de farmácia lançados entre 1920 e 1940, que se constituíam como o grande veículo para a divulgação dos medicamentos e produtos oferecidos pela indústria farmacêutica ou de alimentos e ratificavam uma representação do progresso ligado ao desenvolvimento científico e à vida urbana: “As regras de higiene e as reformas sanitárias podem ser incluídas nesse processo de normatização da sociedade moderna, que tinha na educação da infância um de seus alvos".

Após concluir o curso de duração de um ano para educadora sanitária, em 1932, Virgínia Bicudo realizou estágio de um semestre em 1933, quando foi contratada pela diretoria do serviço de saúde escolar do Departamento de Educação para dar aulas de higiene em educandários da cidade de São Paulo (MAIO, 2010). Foi a partir desta atuação como educadora sanitária que a autora se aproximou das investigações sobre a infância.

\footnotetext{
O trabalho como visitadora psiquiátrica é pautado por tensões, preconceitos e marginalização social. Ele encontra-se distante do consenso. A prática profissional influenciou a perspectiva sociológica de Bicudo ao conceber um mundo marcado pelo conflito social. Essa visada ganhou refinamento sócio-antropológico na ELSP, especialmente no mestrado. (MAIO, 2010, p. 320)
}

Em 1936, Bicudo ingressou no curso superior de Ciências Sociais na Escola Livre de Sociologia Paulista (ELSP), o qual também era uma das alternativas profissionais emergentes para as mulheres. Maio (2010) aponta que a ELSP, em sua emergência, aprofundou e realizou estudos sobre o negro, padrão de vida e assistência filantrópica na cidade de São Paulo, formulou enquetes sobre o preconceito e atitudes raciais, pesquisas de opinião pública, imigrantes, condições de trabalho, higiene mental e psicanálise, experiência social de doenças, estudo de comunidades rurais, projetos de desenvolvimento de comunidade, etnologia, etc. A instituição também contratou muitos antropólogos e sociólogos estrangeiros, dentre eles Donald Pierson (1900-1995). Por inspiração da Escola de Chicago, a instituição adotou a perspectiva interdisciplinar, como nas relações entre as áreas da Antropologia, Sociologia e Psicologia Social. 
Durante a graduação, Virgínia Bicudo teve seu primeiro contato com a teoria psicanalítica, quando frequentava as aulas de Psicologia Social.

\begin{abstract}
Este ensinamento acompanhará Virgínia Bicudo ao longo de toda sua vida, compondo um ponto de equilíbrio bastante interessante, uma vez que esta psicanalista soube investigar os recônditos da vida mental sem, contudo, negligenciar em seu trabalho a abrangência social da psicanálise. (ABRÃO, 2010, p. 59)
\end{abstract}

Bicudo bacharelou-se em Ciências Sociais e Políticas em 1938, sendo a única mulher numa turma de oito alunos. Durval Marcondes, então professor da ELSP, foi um dos articuladores do movimento psicanalítico em São Paulo, sendo que por seu intermédio e iniciativa foi fundada a Sociedade Brasileira de Psicanálise, em 1927.

Naquele momento, havia uma valorização da infância na área da Psicanálise, aspecto muito atrelado ao projeto educacional elaborado pelos reformadores da educação, que se fundamentava em teorias do liberalismo, da democracia, do cientificismo e do industrialismo. O objetivo, como ressalta Gimenes García (2014), era preparar o Brasil para o século XX e, simultaneamente, superar os drásticos problemas do nosso passado colonial, escravista, rural e desigual.

\begin{abstract}
Arthur Ramos e Durval Marcondes foram intelectuais que tiveram uma formação médica em psiquiatria e não restringiram sua atuação a esse campo específico, mas alargaram as fronteiras do conhecimento com a anexação de novas ciências como a antropologia e a psicanálise. Ambos viam na ciência uma possibilidade de intervenção social que teria a educação como meio fértil para a construção de uma nação democrática, moderna e desenvolvida. (GARCÍA, 2014, p. 954)
\end{abstract}

Os pares saúde e educação eram, portanto, problemas indissociáveis; ambas as esferas buscavam atrelar seus saberes, a partir da perspectiva moderna, experimental e científica. Tanto para Ramos como para Marcondes, a infância era vista como o período essencial para se evitar o surgimento de pessoas “desajustadas” e despreparadas para o convívio social saudável (GARCÍA, 2014).

Elisabeth Mokrejs (1987) adverte que os trabalhos de Arthur Ramos valorizavam o estudo da infância como uma etapa significativa em oposição às preferências dos estudos antropológicos do período pelo branco, adulto e o civilizado. O autor contestava a rotulação discriminatória de "anormalidade" para determinados distúrbios de conduta, bem como fazia grandes ressalvas às tentativas simplistas de uma testologia 
primária, que visava à homogeneização psicológica da criança, sem o exame de todos os fatores que influenciavam nas suas fachadas de personalidade e comportamento; por isso a extensão das análises das crianças também em seus ambientes familiares e sociais.

Abrão (2014) assinala que a criança foi concebida naquele momento como um ser diferenciado do adulto, com características de desenvolvimento e aprendizagem próprias e, por isso, eram necessários estudos sobre a singularidade da infância, área que a psicologia e a psicanálise começavam a teorizar nas primeiras décadas, sendo que a forma como a psicanálise foi introduzida no Brasil, menos como um instrumental terapêutico e mais como um sistema teórico conceitual, favoreceu sua difusão prioritária no meio educacional.

\begin{abstract}
A atuação conjunta desses profissionais garantia que a criança fosse avaliada sob a perspectiva tanto orgânica quanto emocional, bem como possibilitava que no plano terapêutico proposto para solucionar suas dificuldades envolvesse uma diversidade de ações que iam desde uma diversidade de ações, que iam desde a psicoterapia direta com a criança até a uma intervenção em seu meio social. (ABRÃO, 2010, p. 94)
\end{abstract}

Jurandir Freire Costa (1976) explicita que, a partir dos anos 1920, a ação terapêutica deveria exercer-se no período pré-patogênico e teria um caráter preventivo, pois o alvo de cuidado dos psiquiatras passou a ser o indivíduo "normal” e não o doente; o que interessava era a prevenção e não a cura.

Os psiquiatras acreditavam que o Brasil degradava-se moral e socialmente por causa dos vícios, da ociosidade e da miscigenação racial do povo brasileiro. A prevenção eugênica apareceu-Ihe como instrumento mais rápido e eficaz para sanear esta situação. (COSTA, 1976, p. 15)

As visitadoras psiquiátricas seriam a parte móvel da clínica de orientação infantil, pois elas iam até os locais de inserção das crianças, colhendo suas histórias de vida para compor a equação que explicasse as causas dos problemas vivenciados e, numa segunda etapa, proporcionar aos pais e professores as orientações convenientes em cada caso particular.

[...] atitude objetiva de visitadora, destruída de reações parciais ou pessoais, a segurança em si mesma, inspira confiança e os pacientes se tornam capazes de depoimentos confidenciais. "Transferência" é o termo Psicanalítico descrito como a reação emocional por 
parte do paciente, na qual este reage em função da organização de sua personalidade. A visitadora deve ser capaz de utilizar-se da transferência positiva como meio de usar a transferência como instrumento de estudos das personalidades em questão. (BICUDO, 1941, p. 294)

Assim, percebemos que o campo de atuação da autora teve como interesse intelectual e uma prática profissional bastante ecléticos, que congregavam temas e áreas de atuação tanto no campo da Sociologia como no da Psicanálise. Todo este envolvimento de Virgínia Bicudo com a saúde mental da criança será de suma importância para o desenvolvimento de suas pesquisas realizadas posteriormente.

Em 1942, ela ingressou na Divisão de Estudos de Pós-Graduados e foi orientada por Donald Pierson, defendendo a dissertação de mestrado intitulada Atitudes raciais de pretos e mulatos em São Paulo. Nessa pesquisa, conforme Maio (2010), Virgínia Bicudo orientou-se pelos estudos de Nogueira (1942), ${ }^{3}$ Donald Pierson (1945), ${ }^{4}$ Stonequist $(1937)^{5}$ e por artigos sobre "atitudes sociais", de Robert Park (1931) $)^{6}$ e Faris (1937) 7 . A autora elegeu relatos de pais e alunos de escolas públicas residentes em quatro bairros populares da cidade de São Paulo (Bela Vista, Santana, Barra Funda e Mooca). As entrevistas foram feitas com familiares que frequentavam a Clínica de Orientação Infantil da Seção de Higiene Mental da Secretaria de Saúde do Estado de São Paulo. Também utilizou o Jornal da Frente Negra Brasileira, Voz da Raça.

Os estudos de Pierson sobre a questão racial no Brasil eram vistos por Ramos como a primeira tentativa científica de um estudo sistematizado e objetivo, além de orientarem uma geração de pesquisadores. Em seu clássico livro, resultado das investigações realizadas entre 1935 e 1937, Brancos e pretos na Bahia (1971), Pierson definiu que a discriminação é desigualdade de tratamento e acontece em vários casos, podendo a responsabilidade recair numa coisa e noutra. Ela pode ser individual ou grupal e ainda apresentar-se favorável ou contrária a um dado indivíduo ou grupo. Já o preconceito de raça é uma atitude, seria uma "tendência para agir".

É uma tendência para agir num sentido contrário em relação ao membro de um outro grupo racial presumível ou real; uma tendência para agir de maneira automática e, em alguns casos, mesmo contra a própria pessoa que age. (PIERSON, 1971, p. 42-43)

Porém o fato de essa atitude ser de indivíduos não significa que seja uma atitude individual, mas, ao contrário, é resultado de experiências coletivas. Geralmente é uma atitude assumida por todos os membros do grupo racial em questão e se dirige contra todos os membros de um

3

NOGUEIRA, Oracy. Atitude desfavorável de alguns anunciantes de São Paulo em relação aos empregados de cor. Sociologia, São Paulo, v. 4, n. 4, p.328, 1942. 4 PIERSON, Donald. Negroes in Brazil. Chicago, University of Chicago Press, 1942. STONEQUIST, Everett. The marginal man: a study in personality and culture conflicto. New York: Charles Scribner's Sons, 1937.

6

PARK, Robert E. Human nature, attitudes, and the mores. In: YOUNG, K. (Ed.). Social attitudes. New York: Henry Holt \& Co., 1931. p. 17-45.

7 FARIS, Ellsworth. The nature of human nature, and other essays in social psycology. New York: McGraw-Hill, 1937. 
outro grupo racial, portanto, sendo assim um fenômeno coletivamente derivado, pertence ao domínio da opinião e sentimentos públicos.

Segundo Mendoza (2005), Pierson utilizou diversos procedimentos na pesquisa de campo. Partindo da etnografia e da observação participante, ele faz uma descrição minuciosa da situação racial, segregação racial e miscigenação, ocupação, vestuários, atitudes de grupo, função do mestiço na comunidade, participação de grupos sociais, sociologia, economia. Ele também empregou técnicas de pesquisa de seleção de informantes principais (homens, mulheres, idade, etc.), técnicas de questionário, árvores genealógicas, entrevistas diretas, registros de rituais, casamentos, cerimoniais, concertos musicais, acontecimentos esportivos, arquivos históricos, etc.

Essa metodologia de pesquisa da Escola de Chicago foi incorporada nas investigações de Bicudo sobre a questão racial na cidade de São Paulo. Conforme Janaina Damasceno Gomes (2013, p. 25):

\begin{abstract}
A trajetória de Bicudo revela processos como o da profissionalização feminina pelo magistério e pela formação como educadora sanitária, o ingresso de mulheres no ensino superior, trajetórias de ascensão social de famílias negras e mestiças. Momentos históricos como o marco do higienismo como regulador social, que selou não apenas sua atuação profissional na juventude, mas sua reflexão acadêmica, e que por vezes se mostra conflitiva com novos modelos de análise social.
\end{abstract}

Assim, podemos observar que uma das grandes contribuições da autora foi levar a psicanálise paulista para espaços científicos e institucionais fora da esfera da medicina (ABRÃO, 2010). Além disso, no que diz respeito às suas pesquisas focadas na infância, Bicudo abandonou as formulações de cunho biológico da educação sanitária e se ancorou numa perspectiva culturalista, além de localizar a raça como categoria social nas pesquisas com crianças.

\title{
AS PESQUISAS COM AS CRIANÇAS
}

Em 1944, Florestan Fernandes já havia empreendido pesquisas com crianças da cidade de São Paulo, cujo resultado foi o trabalho intitulado "As trocinhas do Bom Retiro" (FERNANDES, 2004), que se trata de uma pesquisa realizada pelo autor numa disciplina de curso de Ciências Sociais, momento em que colhia dados sobre o folclore infantil paulistano, analisando as cantigas de ninar e de acalanto, cantigas de piquenique, brinquedos de salão, lendas e fábulas advindas popularmente, superstições, ditos e provérbios, etc. 
Para Fernandes (2004), a visão que por muito tempo perdurou que a criança é somente cópia dos adultos - teve consequências funestas do ponto de vista científico, retardando a análise objetiva dos grupos infantis. Ele aponta que um contato com a realidade destas crianças nos faz obter posição diversa, pois o processo de socialização e convivência entre elas é regulado por sua própria vida social. Nesse estudo, Fernandes analisa as categorias de classe, nacionalidade e gênero. Segundo Cruz, Abramowicz e Rodrigues (2015), é consenso, no campo brasileiro da sociologia da infância, que esta pesquisa de Florestan Fernandes é pioneira por descrever as formas pelas quais as crianças estabeleciam um tipo particular de organização social, também a partir de suas particularidades culturais que dinamizavam as relações sociais naquele contexto:

Mas há outros elementos na cultura do grupo infantil. Nem tudo
respondia coisas relativas ou provenientes da cultura dos adul-
tos. Os próprios imaturos também elaboram, é óbvio, parte dos
elementos de seu patrimônio cultural. Alguns desses elementos
foram, mesmo, estruturados sobre moldes fornecidos pela vida
integrativa da "gente grande". Essas criações, todavia, se institu-
cionalizaram, posteriormente, podendo ser aprendidas nos grupos
infantis, como acontece com os elementos aceitos da cultura do
adulto. Tornaram-se, por sua vez, traços folclóricos, coisa crista-
lizada e tradicional. O papel da criança consiste em recebe-los e
executá-los: e as modificações são, como todas as outras do do-
mínio do tradicional, lentas e inconscientes. Exemplo dessas cria-
cões - que supomos infantis - são os brinquedos como "Papai e
Mamãe", "Banqueiro", "Polícia", "Melancia", "Fitas, etc., quase todos
calcados pelos motivos da vida social. (FERNANDES, 2004, p. 247)

A percepção do autor sobre o universo das brincadeiras infantis trouxe grandes contribuições para a análise do protagonismo infantil. Da mesma maneira, as pesquisas realizadas por Virgínia Bicudo nos anos 1950 também conectam as categorias de gênero, nacionalidade, faixa etária e classe social aos estudos das relações raciais em torno das atitudes escolares nas escolas primárias públicas, segundo ela buscou enfatizar: “1) Os sentimentos e os mecanismos psíquicos de defesa manifestos nas atitudes relacionadas com a cor dos colegas; 2) A influência das relações intra-familiais no desenvolvimento daquelas atitudes" (BICUDO, 1955, p. 227). Nesse sentido, o trabalho da autora também pode ser considerado inovador, assim como o de Florestan Fernandes, pois traz - a partir de um campo heterogêneo, interdisciplinar e confluindo abordagens teóricas e metodológicas - a perspectiva da criança para a compreensão das relações raciais na sociedade brasileira. 
Outra pesquisa com crianças integrou o projeto Unesco/Anhembi e foi realizada pela psicóloga polonesa Aniela Meyer Ginsberb (1955), que teve como intuito perceber as atitudes das crianças em idade escolar para com seus colegas brancos e "de cor", a partir dos marcadores de idade, sexo, meio social e a cor dos examinados. Seu procedimento metodológico se inspirou nas técnicas de H.G. Trager, M. Radke e H. Davis, com base no jogo de bonecas, em que as crianças devem escolher entre bonecas negras e brancas, e na "interpretação de quadros representativos".

As pesquisas, de viés empírico, realizadas por Bicudo e Ginsberg são precursoras por conectarem sociologicamente conceitos da ainda incipiente psicanálise no Brasil nas atitudes das crianças, utilizando a escola como espaço abrangente, no sentido de compreender as atitudes delas como pertencentes a grupos escolares em relação ao preconceito racial no espaço escolar paulistano (CRUZ; ABRAMOWICZ; RODRIGUES, 2015). Ainda conforme essas autoras, tais pesquisas podem ser inseridas em uma espécie de gênese histórica da pesquisa sociológica sobre as crianças e suas infâncias no contexto brasileiro.

Segundo Abrão (2008), no momento em que Virgínia Bicudo realizava suas pesquisas com as crianças, havia uma circulação importante das teorias da psicanalista Melanie Klein (1882-1960) no Brasil, cujas ideias foram difundidas principalmente na psicanálise de crianças, com maior ênfase na década de 1950. Klein, em seu livro A psicanálise de crianças (1997), apontou que as observações psicanalíticas ensinaram que a criança, mesmo nos seus mais tenros anos, experimenta não apenas impulsos sexuais e ansiedade, mas também grandes desapontamentos. Concomitantemente a isso, havia a falsa crença na assexualidade da criança, que vivenciava uma espécie de “paraíso da infância”, mas suas conclusões, tiradas a partir da análise dos adultos e da observação direta de crianças, demonstraram que a criança possuía condições de estabelecer uma relação transferencial com um adulto estranho: "Descobrir, como descobrimos, que mesmo crianças muito pequeninas acham-se sob pressão de sentimentos de culpa dá-nos pelo menos uma precondição para a análise da criança pequena” (KLEIN, 1997, p. 27).

O trabalho de Bicudo sobre as atitudes dos alunos dos grupos escolares em relação com a cor de seus colegas se fundamentou em estudos de caso e entrevistas. É válido observar que em sua dissertação de mestrado a então pesquisadora já havia realizado entrevistas com as crianças e com familiares que frequentavam a Clínica de Orientação Infantil, na Seção de Higiene Mental da Secretaria de Saúde do estado de São Paulo. Como observa Gomes (2013), foi a função de visitadora psiquiátrica que lhe permitiu abordar o "ajustamento da personalidade" dos escolares, pretendendo, assim, analisar o ambiente afetivo dos estudantes e realizando esse processo num momento em que a profissão 
de socióloga e a pesquisa de campo nas grandes cidades ainda eram incipientes.

\begin{abstract}
A escola teria um papel importante pois era onde as diferenças se encontravam e representava um esforço de homogeneização do cidadão nacional. Aqui é interessante notar como as escolas e a educação começam a surgir como campo de investigação nas ciências sociais brasileiras. (GOMES, 2013, p. 100)
\end{abstract}

Virgínia Bicudo relata que o material eleito para a pesquisa partiu de uma amostra estratificada dos alunos que frequentavam o terceiro grau dos grupos escolares no município de São Paulo e do estudo de 29 famílias desses alunos. Assim, foram observadas as crianças das classes intermediárias. O método estatístico e o estudo de caso foram os métodos empregados no trabalho. A amostra foi composta por 4.520 alunos com idade entre 9 e 15 anos, classificados em brancos, mulatos, negros. Por mais que não tenham sido estudadas as atitudes referentes aos japoneses, esses foram destacados devido aos seus caracteres raciais aparentes. A amostra foi composta, segundo a cor dos escolares, por brancos $(86,32 \%)$, negros $(6,86 \%)$, japoneses $(3,93 \%)$ e mulatos $(2,89 \%)$. As questões foram formuladas de forma que as respostas oferecessem indicações sobre as atitudes de aproximações e de afastamento entre os escolares na base da cor, partindo das seguintes perguntas: ${ }^{8}$

\begin{abstract}
Perto de quem você gostaria de sentar-se? 2. Por que você gostaria de sentar-se perto desse (ou dessa) colega? 3. Dê o nome de outro (ou outra) colega perto de quem você gostaria de sentar-se? 4. Por que você gostaria de sentar-se perto desse outro (ou dessa outra) colega? 5. Perto de quem você não gostaria de sentar-se? 6. Por que você não gostaria de sentar-se perto desse (ou dessa) colega? 7. Dê o nome de outro (ou outra) colega perto de quem não gostaria de sentar-se? 8. Por que você não gostaria de sentar-se perto desse outro (ou dessa outra) colega? (BICUDO, 1955, p. 228)
\end{abstract}

O objetivo foi obter esclarecimentos a respeito da a natureza psicossocial, das relações de dependência indicadas pela análise estatística e das racionalizações apresentadas nos motivos de preferência ou de rejeição entre os colegas. O conhecimento das atitudes dos escolares com referência à cor dos companheiros de classe constitui um dos objetivos da pesquisa, o qual procurou-se alcançar por via indireta, ou seja, por meio das atitudes de preferência e de rejeição para a escolha de companheiros de banco escolar.

Apontamos para o fato de que Virgínia Bicudo, com esta pesquisa, chegou a resultados diferentes daquela realizada por seu orientador, 
Donald Pierson, na Bahia, que observou que nas escolas, no período estudado, década de 1930, não existia segregação de qualquer espécie, porém os alunos brancos e mulatos claros predominavam. Conforme Pierson analisa, havia uma ordem social de livre competição, na qual os indivíduos pleiteavam posição baseada principalmente em realizações pessoais e favoráveis condições de família. Na determinação do status social, a competência do indivíduo, sua instrução e realizações profissionais, bem como os seus recursos financeiros, tendem a superar a origem racial; porém, a parte "mais escura" da população teve de lutar com as sérias desvantagens de terem seus pais, avós e outros ascendentes "começados de baixo", símbolos indestrutíveis de status inferior.

É interessante pontuar, a partir da reflexão de Florestan Fernandes (2007), no artigo “O negro em São Paulo”, originalmente publicado em 1968, que os padrões de organização da economia, da sociedade e da cultura não tiveram uma vigência universal, como muitas investigações históricas e sociológicas apontaram por muito tempo. No caso da história do negro em São Paulo, essa população seguiria rumos bem diversos dos que podem ser notados na evolução da Bahia, Pernambuco, ou Rio de Janeiro.

Pode-se concluir que, pelo menos, até o presente, o negro não conseguiu, no Estado de São Paulo, uma acomodação econômica, social e culturalmente compensadora, seja no nível da economia urbana (como ocorreu em cidades como o Recife, Salvador ou mesmo Rio de Janeiro). Em consequência, sua presença como agente de preservação cultural foi aqui menos relevante. (FERNANDES, 2007, p. 174)

Roger Bastide (1955b), em um de seus artigos da coletânea Unesco/ Anhembi, intitulado "Manifestações do preconceito de cor", argumenta que as manifestações do preconceito são heterogêneas e seus disfarces múltiplos e, da mesma forma, as atitudes raciais variam conforme os setores da sociedade, as famílias ou as pessoas. Por detrás deste caos aparente, existiriam certas regularidades ou "leis". Haveria nas relações raciais paulistanas uma espécie de “tabu de cor”, que se aprende desde a infância, na medida em que se desenvolve na criança branca um duplo mecanismo de comportamento: paternalista em relação aos negros e igualitário em relação aos brancos, sendo que nesta espécie de sentimentalismo encontrar-se-ia diluído o preconceito, que aparece na ausência de um sistema de reciprocidade nas relações entre negros e brancos.

A partir da pesquisa realizada em São Paulo, Virgínia Bicudo concluiu que os motivos de preferência ou de rejeição revelavam que a justificativa das escolhas por motivos raciais apareceu apenas em 0,22\% das respostas de rejeição. Com o objetivo de analisar de modo mais acurado a natureza psicossocial sobre as relações de dependência indicadas pela 
análise estatística e sobre as racionalizações apresentadas nos motivos de preferência e de rejeição, a investigação selecionou 30 escolares para realizar entrevistas com seus pais, entretanto, efetivamente só foram entrevistados 29, pois, como a autora explica, deixou-se de estudar o único caso de escolar negro preferido por não ter-se conseguido encontrar sua residência.

Os escolares e seus pais foram estudados por um motivo racial. Os
29 escolares e seus pais foram estudados por meio de entrevista,
procurando conhecer-Ihes os traços da personalidade, o ajusta-
mento entre os membros de sua família e as atitudes referentes às
pessoas de cor. (BICUDO, 1955, p. 229)

Dentre os 29 entrevistados, havia 13 escolares brancos preferidos, nove escolares brancos rejeitados, cinco escolares negros rejeitados, um escolar mulato rejeitado e um escolar branco. Dos 13 primeiros casos, as entrevistas revelaram que três alunos viviam em condições familiares desfavoráveis ao desenvolvimento "sadio da personalidade”.

O fato de todos os escolares mais preferidos serem brancos, como
exceção de 1 que era negro, reforça a hipótese de os escolares have-
rem identificado o branco com as boas qualidades. A escolha de um
negro preferido indica que essa identidade pode ser superada quan-
do o negro apresenta "qualidades de branco". (BICUDO, 1955, p. 248)

A pesquisa Unesco apontou que havia uma preferência muito acentuada e geral pelo escolar branco, o qual determinou o padrão das escolhas dos grupos de minoria, seguindo-se, com porcentagens muito baixas, as preferências pelo negro, pelo japonês e pelo mulato. Entretanto, para que esta conclusão fosse possível, a autora teve que investigar para além das aparências fornecidas pelas respostas às perguntas das entrevistas, cujos motivos atestados para sentar-se ou não perto de determinado colega variavam nos seguintes adjetivos: "bem-educado”, “obediente”, “agradável”, “alegre”, “carinhosa”, “bonito”, “meu vizinho", "meu primo”. Já as razões para não se sentar ou não querer ser amigo do colega eram: "mau aluno”, “conversador”, “copiador", “cabulador”. As respostas rejeitadoras explicadas por um "motivo racial" corresponderam a apenas $0,22 \%$, o que levou Bicudo a concluir que o mascaramento das atitudes em relação à cor tenha ocorrido em função de uma identidade do branco com as qualidades apreciadas e do não branco com as qualidades não apreciadas.

A pesquisadora cogitou que a ausência de motivos explicitamente ligadas à cor fundamenta as hipóteses: 
1. Os escolares não tinham consciência de sua discriminação baseada na cor ou os escolares eram conscientes da discriminação, porém, censuraram-na;

2. As qualidades de "bom", ou "bom-aluno", "bem-educado", estariam associadas ao branco, como qualidades a ele peculiares. (BICUDO, 1955, p. 240)

Analisando as entrevistas com as crianças, a pesquisadora concluiu que, das 8.072 respostas sobre os motivos pelos quais os escolares rejeitavam os colegas, somente em 18 apareceu explicitamente um motivo racial: 11 escolares não gostariam de sentar-se com o colega "porque ele é preto" ou "porque ele é de cor” ou "porque ele é um negrinho mal-educado" ou "porque ele é moreno"; cinco escolares rejeitaram o colega "porque ele é japonês"; um "porque ele é sírio”; e um "porque ele é cabeça chata”. Desses escolares, 15 eram brancos, dois japoneses e um mulato.

Preto, de cor, e moreno foram as expressões empregadas, demonstrando que os escolares censuravam a palavra negro que é muito mais agressiva e já responde a um xingamento. Esta mesma atitude de evitar usar o termo negro foi observada nas entrevistas com os adultos. (BICUDO, 1955, p. 270)

Bicudo, ao considerar a escola unidade empírica de investigação, reconhece também que existem componentes não escolares que penetram a escola e o comportamento de seus agentes. Conforme Marília Sposito (2003), essa perspectiva da sociologia da educação é denominada pela autora como não escolar, exclusivamente, e marcou os estudos desta área no Brasil nos anos 1950 e 1960, quando ocorreu uma ênfase trabalhos desenvolvidos pela sociologia paulista na época sobre a temática e ressalta que essa reflexão foi muito enfatizada no trabalho de Antonio Candido (1973), em artigo intitulado "Tendências do desenvolvimento da sociologia da educação", originalmente publicado em 1955. O autor afirmou que a escola deve ser vista como uma "unidade social", que determina tipos específicos de comportamento e suas relações com as instituições sociais, sendo que a circunstância de receber estatuto, normas e valores da sociedade não deve tornar incapaz a análise do que nela se desenvolve como resultado da sua própria dinâmica. maior nas relações entre mudança social e mudança educacional, já que houve compreensão de que as instituições educacionais devem ser entendidas a partir de processos dinâmicos e dos sujeitos que as compõem. Desse modo, houve a abrangência da seguinte hipótese investigativa: sair dos limites físicos da instituição, para melhor compreendê-la sob a perspectiva de processos sociais dinâmicos e a partir dos sujeitos que a ela aspiravam. ${ }^{9}$

Assim, é importante ressaltar que, no campo da sociologia da educação, como aponta Agnès Van-Zanten (1988), os elos sociais entre as famílias e as instituições escolares sempre estiveram no centro das preocupações da área, porém muitos sociólogos realizaram análises macroscópicas e estatísticas entre a posição social dos pais e a performance escolar dos filhos, desprezando os processos e as dinâmicas intrafamiliares, as práticas socializatórias e as estratégias educativas ao microcosmo familiar. Bicudo, ao realizar seus estudos, buscou observar as interações 
entre instituição familiar e escolar, cujo argumento central eram as relações raciais.

Durante as entrevistas com os pais desses alunos preferidos, os pais demonstravam os sentimentos de discriminação racial, definindo os negros nos seguintes termos: "pessoas inferiores”, "não prestam", "são vagabundos", "macumbeiros”, "bêbados”, "jogadores”, "relaxados", "briguentos”, “desejam mal”, etc. As mães seguiam as opiniões dos maridos. Bicudo afirma que notou nesses entrevistados uma racionalização dos seus sentimentos de hostilidade contra os pretos utilizando como subterfúgio os estereótipos, o que demonstrava uma necessidade de justificar-se e aliviar-se do sentimento de culpa, que acompanha os sentimentos ligados à discriminação.

Uma das professoras também entrevistada demonstrou ambiguidades em suas atitudes para com as "pessoas de cor", afirmando que não tinha nada contra o preto, desde que seja educado; em seguida negou essa opinião ao dizer que não gostaria de ter uma parente preta, porque o "preto é raça inferior". Essa visão da professora é reforçada quando diz que o índio se demonstrou superior não se deixando escravizar, ao passo que o negro nasceu para ser escravo, opinião, segundo Bicudo, comumente expressada por professores primários nas aulas de História do Brasil.

Esta concepção, que tinha por intuito estabelecer uma hierarquia das raças no Brasil, desvalorizando ainda mais a população negra, dominou o pensamento social por muito tempo no Brasil. Os determinismos biológicos, geográficos e culturais insistiam em classificar as raças em mais fortes e menos fortes. Bastide (1955b) aponta que o preconceito de cor neste período dos anos 1950 persistia e se baseava em antigos estereótipos.

\footnotetext{
O preconceito de cor, cuja função era justificar o trabalho servil do africano vai servir agora para justificar uma sociedade de classes, mas nem por isso vão variar os estereótipos antigos; mudarão apenas a finalidade. Entretanto, um novo tipo de preto afirma-se cada vez mais, com a transformação do escravo em cidadão, e o branco não sabe mais que atitude tomar para com ele, pois os estereótipos tradicionais já não se aplicam a esse negro que sobe na escala social. (BASTIDE, 1955b, p. 11)
}

Ao entrevistar os pais das crianças negras rejeitadas, Bicudo concluiu que suas atitudes também demonstravam que eles tinham hostilidade contra as "pessoas de cor" e contra si próprios, tendo introjetado os ideais do branco. Ao reprimirem a hostilidade contra o branco, eles deslocam a agressividade para o próprio negro, vendo o branco como ideal, respeitado e amado, entretanto, também temido e odiado: 
O ódio e o medo objetivaram-se nos estereótipos referentes a cor e foram transmitidos à criança pelos próprios pais. Considerados pelos brancos como inferiores, maus, bêbados, ladrões, macumbeiros, vagabundos e briguentos, e tendo introjetado estes conceitos, as pessoas de cor passam a tratar o negro e, portanto, a si próprios com desprezo e ódio, sentimentos estes que vão influir no desajustamento da personalidade, nos conflitos intrafamiliais e na desorganização da família negra. (BICUDO, 1955, p. 269)

Segura-Ramírez (2006) aponta que a pesquisa de Bicudo demonstra a importância da observação minuciosa das dimensões psíquicas e comportamentais, das relações raciais, principalmente sobre a configuração das atitudes e dos estereótipos e a delimitação do habitus racial brasileiro: a exclusão dos negros e mulatos do campo da consciência dos brancos; as atitudes ambivalentes (rejeição e aceitação) nas pessoas negras em relação aos brancos quanto a si mesmos; a introjeção já na escola de uma etiqueta racial que dissimula as verdadeiras ideias que o grupo branco tem em relação às pessoas de cor; e a censura e a racionalização como princípios que justificam a discriminação dos brancos por meio da estigmatização e da atribuição do signo da inferioridade humana à população negra.

Conforme Maio (2010), no período pós-guerra, as pesquisas sobre as atitudes raciais (preconceitos e estereótipos) enfatizam as críticas ao determinismo biológico, ao suposto caráter inato das ações humanas, buscando as razões psicossociológicas das hostilidades entre grupos sociais étnicos, religiosos e econômicos. Os estudos de estereótipos, atitudes, caráter nacional foram alguns dos tópicos da agenda de pesquisa em ciências sociais. A participação de Bicudo no projeto Unesco contribuiu para a produção de um conjunto de dados e análises sistematizados sobre o preconceito e a discriminação racial no Brasil.

\section{CONSIDERAÇÕES FINAIS}

Podemos observar que Virgínia Bicudo teve como grande desafio em sua pesquisa compreender as relações raciais no Brasil num contexto de transição e de mudanças na sociedade, que, a partir de 1950, passava por um processo de modernização em diferentes esferas. Um dos grandes méritos da autora foi a valorização da infância naquele momento. Além disso, outro argumento importante trazido pelas suas pesquisas sociais, de base empírica, foi desmistificar as relações harmoniosas presentes na sociedade brasileira. Ao contrário do que pensavam alguns intelectuais estrangeiros, o racismo e o preconceito eram sentidos no cotidiano e na socialização dos escolares negros, apesar de a discriminação raramente ser assumida pelos entrevistados. 
Em suas pesquisas pode-se observar também que o modelo de infância brasileiro difundido no final do século XIX e início do XX legitimava a “criança saudável”, por isso a importância da relação medicina e escola para o futuro da nação. A condição para uma sociedade civilizada perpassaria obrigatoriamente pela sua composição étnica, e como resultado satisfatório uma homogeneização cultural seria necessária. Portanto, no caso das crianças negras, haveria a necessidade da negação da sua condição racial.

O que podemos ressaltar é que Virgínia Bicudo, portanto, foi uma das primeiras sociólogas a realizar pesquisa social com as crianças e, ao acessar o universo infantil, percebeu que os alunos entrevistados viviam, desde a mais tenra idade, frustrações intensas responsáveis por graves conflitos emocionais que se expressavam nos sintomas de hostilidade exagerada entre os colegas, principalmente quando os conflitos envolviam a condição de não aceitação social da diversidade das etnias. Além disso, podemos enfatizar que as inquietações de Bicudo estavam no sentido de ver a criança de forma holística, não apenas no contexto escolar, estendendo, por conta disso, suas pesquisas e observações ao contexto familiar. Suas preocupações intelectuais no que se refere à infância apresentam um amplo debate direcionado pela interdisciplinaridade, dado o alcance de sua atuação profissional, que foi pensado para além de paradigmas teóricos hegemônicos, pois conferiu protagonismo à criança.

\section{REFERÊNCIAS}

ABRÃO, Jorge Luís Ferreira. Virgínia Leone Bicudo: pioneira da psicologia e da psicanálise no Brasil. Interação em Psicologia, Curitiba, v. 18, n. 2, p. 217-227, maio/ago. 2014.

ABRÃO, José Luís Ferreira. Virgínia Bicudo: a trajetória de uma psicanalista brasileira. São Paulo: Arte\&Ciência; Fapesp, 2010.

ABRÃO, José Luís Ferreira. Considerações históricas sobre a difusão do pensamento kleiniano no Brasil. Revista Latinoamericana de Psicopatologia Fundamental, São Paulo, v. 11, n. 3,

p. 365-379, set. 2008.

ABRAMOWICZ, Anete. A pesquisa com crianças em infâncias e a sociologia da infância. In: FARIA, Ana Lúcia G.; FINCO, Daniela (Org.). Sociologia da infância no Brasil. Campinas: Autores Associados, 2011. p. 17-36. (Polêmicas do Nosso Tempo, 102).

BASTIDE, Roger. Introdução. In: BASTIDE, Roger; FERNANDES, Florestan (Org.). Relações raciais entre negros e brancos em São Paulo. São Paulo: Editora Anhembi/Unesco, 1955a. p. 11-15.

BASTIDE, Roger. Manifestações do preconceito de cor. In: BASTIDE, Roger; FERNANDES, Florestan (Org.). Relações raciais entre negros e brancos em São Paulo. São Paulo: Editora Anhembi/ Unesco, 1955b. p. 123-158.

BASTOS, Elide Rugai. Unesco/Anhembi: um debate sobre a situação do negro no Brasil. In: PEREIRA, Cláudio; SANSONE, Lívio (Org.). Projeto Unesco no Brasil: textos críticos. Salvador: Edufba, 2007. p. 251-269. 
BICUDO, Virgínia Leone. Atitudes dos alunos dos grupos escolares em relação com a cor dos seus colegas. In: BASTIDE, Roger; FERNANDES, Florestan (Org.). Relações raciais entre negros e brancos em São Paulo. São Paulo: Editora Anhembi/Unesco, 1955. p. 227-310.

BICUDO, Virgínia Leone. A visitadora social psiquiátrica e seu papel na higiene mental da criança. Revista de Neurologia e Psiquiatria de São Paulo, São Paulo, v. 7, n. 6, p. 293-298, 1941.

CANDIDO, Antonio. Tendências no desenvolvimento da sociologia da educação. In: PEREIRA, Luiz; FORACCHI, Marialice M. Educação e sociedade: leituras de sociologia da educação. São Paulo: Companhia Editora Nacional, 1973.

COSTA, Jurandir Freire. História da psiquiatria no Brasil. Rio de Janeiro: Documentário, 1976.

CRUZ, Ana Cristina Juvenal da; ABRAMOWICZ, Anete; RODRIGUES, Tatiane Cosentino. A pesquisa sobre criança e infância no Projeto UNESCO. Revista Eletrônica de Educação, São Carlos, v. 9, n. 2, p. 321-345, 2015.

GARCÍA, Ronaldo Aurélio Gimenes. Arthur Ramos e Durval Marcondes: higiene mental, psicanálise e medicina aplicadas à educação nacional (1930-1950). Educação \& Sociedade, Campinas, v. 35, n. 128, p. 951-966, jul./set. 2014.

GINSBERG, Aniela. M. Pesquisas sobre as atitudes de um grupo de escolares de São Paulo em relação com as crianças de cor. In: BASTIDE, Roger; FERNANDES, Florestan (Org.). Relações raciais entre brancos e negros em São Paulo. São Paulo: Editora Anhembi/Unesco, 1955. p. 311-361.

GOMES, Janaína Damaceno. Os segredos de Virgínia: estudo das atitudes raciais em São Paulo (1945-1955). 2013. 166 f. Tese (Doutorado em Antropologia) - Universidade de São Paulo, São Paulo, 2013.

FERNANDES, Florestan. O negro em São Paulo. In: FERNANDES, Florestan. 0 negro no mundo dos brancos. São Paulo: Global, 2007. cap. VI, p. 153-182.

FERNANDES, Florestan. As “trocinhas” do Bom Retiro. Pro-Posições, v. 15, n. 1, p. 229-250, jan./abr. 2004.

KLEIN, Melanie. A psicanálise de crianças. Rio de Janeiro: Imago, 1997.

KUHLMANN JR., Moysés; MAGALHAES, Maria das Graças Sandi. A infância nos almanaques: nacionalismo, saúde e educação (Brasil 1920-1940). Educação em Revista, Belo Horizonte, v. 26 n. 1, p. 327-349, abr. 2010 .

MAIO, Marcos Chor. Educação sanitária, estudos de atitudes raciais e psicanálise na trajetória de Virgínia Leone Bicudo. Cadernos Pagu, Campinas, n. 35, p. 309-355, 2010.

MAIO, Marcos Chor. O Projeto UNESCO e a agenda das ciências sociais no Brasil dos anos 40 e 50. Revista Brasileira de Ciências Sociais, São Paulo, v. 14, n. 41, p. 141-158, out. 1999.

MENDOZA, Edgar S.G. Donald Pierson e a escola sociológica de Chicago no Brasil: os estudos urbanos na cidade de São Paulo (1935-1950). Sociologias, Porto Alegre, n. 14, p. 440-470, jul./dez. 2005.

MOKREJS, Elisabete. Psicanálise e educação: Artur Ramos: um episódio na história da educação no Brasil. Revista da Faculdade de Educação, São Paulo, v. 13, n. 1, p. 91-104, jan./jun. 1987.

PIERSON, Donald. Brancos e pretos na Bahia: estudos de contacto racial. São Paulo: Companhia Editora Nacional, 1971.

ROCHA, Heloísa Helena Pimenta; GOUVEA, Maria Cristina Soares de. Apresentação. Educação em Revista, Belo Horizonte, v. 26, n. 1, p. 187-194, abr. 2010.

ROCHA, Heloisa Helena Pimenta. A educação sanitária como profissão feminina. Cadernos Pagu, Campinas, n. 24, p. 69-104, jan./jun. 2005.

ROSEMBERG, Fúlvia. Raça e educação inicial. Cadernos de Pesquisa, São Paulo, n. 77. p. 25-34, maio 1991.

SEGURA-RAMÍREZ, Hector F. Tiro no pé: biopolítica, relações racializadas, academia e poder no Brasil 1823-1955/1997-2006. 2006. 352 f. Tese (Doutorado em Ciências Sociais) - Universidade Estadual de Campinas, Campinas, 2006. 
SPOSITO, Marilia P. Uma perspectiva não escolar no estudo sociológico da escola. Revista USP, São Paulo, n. 57, p. 210-226, mar./maio 2003.

VAN-ZANTEN, Agnès. H. Les families face à l'école: rapports institutionnels et relations sociales. In: DURNING, Paul (Org.). Education familiale: un panorama des recherches internationales. Paris: MIRE/Matrice, 1988. p. 185-207. 